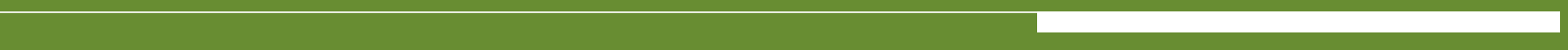

SECCIÓN: Teorías geográficas, geografía de la

cultura y la vida cotidiana
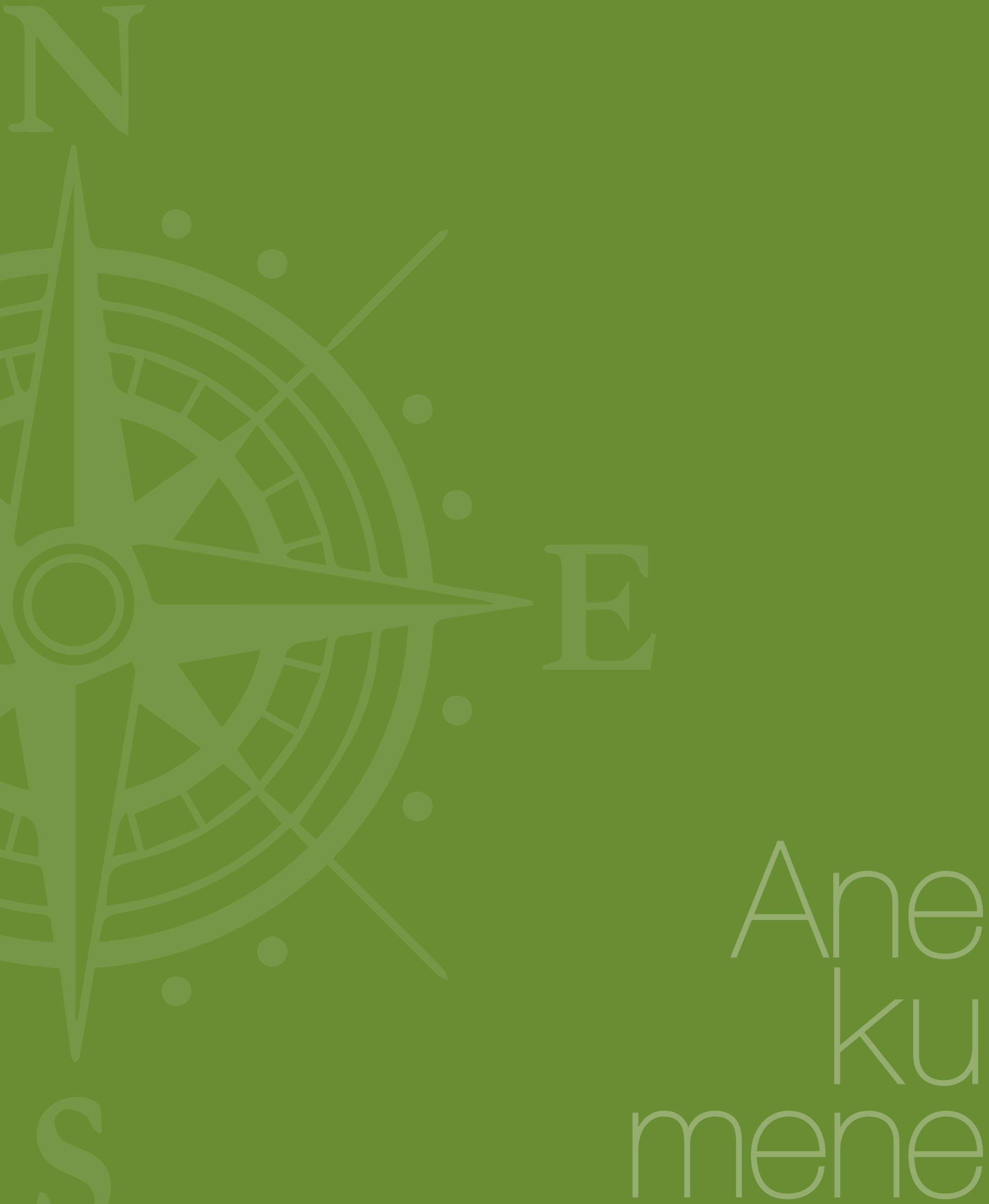


\section{Creaciones pictóricas y cartografía narrada: Una forma de acercarnos a la experiencia del lugar rural ${ }^{1}$}

\section{Creações pictóricas e cartografia narrada:} Uma forma de acercar-nos à experiência do espaço rural Pictorial Creations and Narrated Cartography: An Approach to Rural Place Experience

Marcela Cuevas Farfán²

\section{Resumen}

El presente artículo se interesa por exponer una lectura comprensiva de la ruralidad visualizando las concepciones que niños y adolescentes ${ }^{3}$ tienen del espacio que habitan. Mediante la Pintura, que nos ubica en el mundo vivido de quien la elabora, y la Cartografía narrada como una forma de acercarnos a la experiencia del lugar, se da cuenta de la experiencia espacial subjetiva y los significados comunes que atribuyen al espacio sus habitantes, para comprender dinámicas rurales asociadas con el habitar y la construcción del lugar desde la cotidianidad. La investigación se inscribe en los estudios cualitativos, el método etnográfico y la geografía humanística con los aportes de la fenomenología y el existencialismo.

\section{Palabras clave}

Ruralidad;

experiencia perceptiva;

cotidianidad; creaciones pictóricas;

cartografía narrada

\footnotetext{
1 Artículo derivado del proyecto de investigación Construcción del espacio rural: una mirada a la experiencia perceptiva de niños y adolescentes adelantado en la Maestría en Estudios Sociales de la Universidad Pedagógica Nacional, dirigido por el profesor César Ignacio Báez. Línea de investigación Construcción Social del Espacio-Grupo Geopaideia.

2 Docente de institución educativa pública de Cundinamarca, Colombia.

3 La investigación se desarrolla con niños y adolescentes entre 9 y 16 años, estudiantes de la Institución Educativa Rural Departamental Ernesto Aparicio Jaramillo, ubicada en zona rural de la inspección La Esperanza del municipio de La Mesa, Cundinamarca, Colombia.
} 


\section{Resumo}

\section{Palavras-chave}

Ruralidade; a experiência perceptiva; vida quotidiana; criações pictóricas; cartografia narrado
Este artigo centra-se na exposição de uma leitura compreensiva da ruralidade visualizar os conceitos que as crianças e adolescentes têm o espaço que habitam. Através da pintura, o que nos coloca no mundo que viveu prepara e cartografia narrado como uma forma de aproximar a experiência do lugar, percebe experiência espacial subjetiva e significados comuns que atribuem os seus habitantes para o espaço para entender dinâmica rural associado com a habitação e construção do lugar da vida quotidiana. A investigação se inscreve em estudos qualitativos, o método etnográfico e geografia humanística com as contribuições da fenomenologia e do existencialismo.
Keywords

Rural character; perceptual experience; everyday life; pictorial creations; narrated cartography

Keywords
Rural character;
perceptual experience;
everyday life; pictorial creations;
narrated cartography

\section{Abstract}

This paper focuses on presenting a comprehensive reading of rural character, highlighting children and adolescents' concepts about the space they inhabit. Through painting, -which places us in the lived world of the artist who painted it, and narrated cartography as a way to approach the experience of place, the paper accounts for subjective spatial experience and common meanings inhabitants attribute to their space in order to understand rural dynamics associated with dwelling and the construction of place from everyday life. The research falls into qualitative studies, the ethnographic method and humanistic geography, with the contributions of phenomenology and existentialism. 


\section{Introducción}

Cualquier observador que camine por el campo colombiano hoy y que lo haya conocido treinta o cuarenta años atrás, reconocerá que han ocurrido muchas transformaciones económicas, políticas, sociales y culturales en estos espacios. Los paisajes ya no son los mismos, y se percibe que la ciudad ha llegado a regiones y poblaciones que parecían apartadas. Aun así, habrá otros observadores que opinarán que son espacios que aún viven en la quietud y el aislamiento. Sin embargo, la globalización ha generado diferentes fenómenos en las sociedades rurales: el avance de la urbanización, la diversificación de las actividades, cambios en los estilos de vida, rupturas generacionales y complejas e intensas interconexiones y relaciones; esto ha provocado que cambien aspectos de su vida diaria y da la impresión de que los espacios rurales se han desdibujado.

Hoy se hace necesario hacer evidentes estas transformaciones desde las distintas miradas de quienes observan y de quienes son observados, $y$ muchas veces se convierten en actores de enorme trascendencia. La presente investigación se interesa por la relación que los niños y adolescentes establecen con su espacio rural, cómo lo viven, cómo lo sienten, lo nombran, lo significan, lo apropian, cómo lo reconocen, cómo despliegan sus intereses, sus pasiones y sus deseos. Hasta el momento esta población se ha constituido en las investigaciones como observadores en silencio y sujetos pasivos en los discursos sobre lo rural.

Así mismo, se acude a las creaciones pictóricas y a la cartografía narrada como formas para explorar el mundo de la percepción, acercarnos a la experiencia del lugar y comprender dinámicas rurales asociadas con el habitar y la construcción de lugares desde las prácticas cotidianas. Esto permite comprender el espacio rural en cuanto a los significados socialmente compartidos que le atribuyen sus habitantes, tener en cuenta sus puntos de vista, creencias y experiencias perceptivas, a fin de poder construir una lectura de su realidad.

El artículo se encuentra dividido en cuatro apartados. En el primero se expone el horizonte teórico, que tiene como base los postulados de la geografía humanística, especialmente desde el enfoque fenomenológico existencial, y el constructivismo geográfico. En el segundo apartado se desarrolla el diseño metodológico. El tercero, da cuenta de los resultados de la experiencia espacial de los sujetos que habitan el espacio rural, a partir de sus prácticas cotidianas. Finalmente, se ponen a consideración los aportes que emergen de las experiencias perceptivas de los niños y adolescentes en la explicación de la realidad rural.

\section{Espacios rurales desde la cotidianidad: Una construcción social del lugar}

En este apartado se exponen los principales referentes teóricos en torno a las categorías experiencias perceptivas, cotidianidad, espacio rural y lugar, las cuales configuran y definen el problema investigativo en busca de hacer evidentes las concepciones el espacio rural presentes en niños y adolescentes que lo habitan. El horizonte teórico que se plantea tiene como base los postulados de la geografía humanística, especialmente desde el enfoque fenomenológico existencial, y el constructivismo geográfico.

\section{Espacio rural, experiencia perceptiva y cotidianidad}

Realizar una definición de los espacios rurales es remitirse a la distinción que históricamente se ha establecido entre lo rural y lo urbano, entre campo y ciudad. Sin embargo, como lo afirma Capel (1975) en "épocas anteriores a la revolución industrial, era probablemente, neta e indiscutible; sin embargo, dicha distinción parece hoy mucho menos clara" (p. 1). En efecto, los procesos de cambio que propician la sociedad informacional y globalizada han provocado una transformación tecnológica y ecológica de estos espacios, de manera que hoy no es fácil percibir las diferencias en hábitos, actitudes y valores, y menos aún en lo que se refiere a las estructuras y relaciones de producción, entre lo urbano y lo rural, lo que hace confusa y problemática esta distinción.

Los rasgos que con más frecuencia se han considerado para caracterizar lo rural han sido, fundamentalmente, el tamaño y la densidad, las actividades agrícolas y el modo de vida, así como ciertas características sociales y el grado de interacción social. Por tanto, el concepto de espacio rural ha estado ligado al de espacio urbano, para hacer notar sus diferencias y oposiciones. Molinero y Alario (1994) coinciden en que lo rural deja de ser un concepto cuantitativo para pasar a ser un concepto de carácter cualitativo.

La presente investigación entiende la ruralidad como una realidad percibida y construida socialmente, resultado de la experiencia directa y profunda con el mundo, cargado de afectos y sentido y que, como tal, es la base misma de la existencia humana donde se materializa el acto de vivir. La construcción de lo rural "no sólo se establece sobre morfologías, paisajes, arquitecturas, tamaño de localidades, sino también sobre costumbres, sentimientos, pensamientos, comportamientos o conductas" (Paniagua, 2004, p. 127). Por tanto, no es posible concebir un espacio rural único, sino que existen diferentes espacios rurales sobre un mismo espacio geográfico rural de acuerdo a las experiencias perceptivas que ligan a las personas con los lugares que habitan. 
Los espacios rurales como construcción social pueden mirarse desde tres ámbitos (Soja, 1997): los espacios de representación o espacios vividos por sus habitantes y usuarios del espacio; las prácticas espaciales; y las representaciones del espacio que tienen que ver con el espacio dominante en cualquier sociedad. De esta manera, las distintas características que enriquecen lo rural están relacionadas con lo cultural pues cada grupo social puede generar su propia representación espacial; la heterogeneidad de las distintas actividades rurales; los flujos de producción y de comercialización de los productos, la movilidad de las personas y las mercancías, entre otras. Desde este enfoque, se permite observar otras características espaciales de lo rural en el mismo lugar en que anteriormente se habían analizado y no se consideraban.

Los espacios rurales son complejos y polifacéticos, puesto que la sociedad los crea y recrea, con sus propias representaciones y proyectos; mediatiza al tiempo que vehicula la representación y las prácticas sociales. Este espacio tiene una doble dimensión: es a la vez material y representación mental, objeto físico y objeto mental. Según Buttimer (1992) el espacio es una realidad mental y subjetiva sometida a la percepción particular de cada individuo, por tanto se describen las cosas tal como las experimentan las personas en la vida cotidiana, como las ven, las oyen, las sienten, las palpan, las huelen, las recuerdan o las imaginan. Se necesita la descripción de las relaciones sensoriales, lo mismo que sus juicios y sus valoraciones. De allí que cobren importancia las experiencias perceptivas o las distintas formas en que una persona conoce y construye la realidad, así como las relaciones que el sujeto establece con el mundo o su contexto:

La experiencia perceptiva es el camino tomado por todos los seres humanos para aprender sobre el mundo que le rodea, ocurriendo cuando el hombre se identifica con el conjunto en el entorno y trata de entender su significado. Así, la experiencia perceptiva busca el sentido de las cosas, guiado por la observación y teniendo en cuenta el contexto en el que opera (Merleau-Ponty, 1975, p. 234).

Es decir, las experiencias perceptivas las integran tanto los sentidos y significados como las actividades y acciones (prácticas) que realiza el ser humano. Nos sumergen en el mundo de la vida cotidiana pues "son actos (actos intencionales) sobre los que se construye el conocimiento de la vida, es la forma más inmediata para dar al mundo sentido" (Akira, 2013, p. 42). Por consiguiente, las experiencias perceptivas involucran actos de simbolización pues revelan la variedad de relaciones que se establecen entre individuo, sociedad y lugar.

Se puede decir que la ruralidad se convierte en espacio de la cotidianidad y reflejo de la misma, puesto que el sujeto toma como escenario de sus actividades cotidianas su entorno inmediato y sobre este desarrolla sus prácticas, experiencias y vivencias; nuestra cotidianidad está "constituida por un conjunto de ritmos y rutinas estructurados por la localización en el espacio y en el tiempo" (Bosque Sendra, 1992, p. 15). Por lo anterior, se asume la cotidianidad como esa condición de lugar donde se dan las prácticas y las experiencias de niños y adolescentes, donde se generan y entran en juego sus sentimientos, ideas, símbolos, significados, entre otras construcciones, tanto personales como colectivas.

De manera que cobra importancia la forma en que los habitantes nombran su localidad y sus lugares, trazan y recorren los caminos, describen sus paisajes, institucionalizan sus espacios, por lo que es necesario tomar en cuenta los lugares de residencia, las vivencias, los recuerdos, las ocupaciones, así como las actitudes negativas o positivas sobre los sitios cotidianos. Es por eso que el espacio rural se constituye como un espacio vivido, como un lugar en el cual se construye la existencia individual, que se enriquece de los intercambios sociales, las cargas emotivas, las imágenes y los conceptos individuales.

Los espacios rurales son vividos, percibidos y representados, se naturalizan por medio de las subjetividades y relaciones en las que cotidianamente están adheridos los sujetos, y generan en cada uno fobias y filias (Lindón, 2006, p. 386), que son consecuencia del contenido afectivo que va adquiriendo el ser humano en el momento que comparte y dialoga con el otro o consigo mismo en un espacio determinado. Permiten la diferenciación de las acciones de cada individuo o de cada comunidad, con respecto a la forma de relacionarse, sentirse, emocionarse y principalmente razonar las actuaciones que llevan a cabo, según la pertinencia que tenga con lo que se está viviendo en el momento, con los otros y el contexto social. Los espacios rurales están llenos de significados y valores, inseparables de la experiencia de quienes lo habitan, de sus pensamientos y sentimientos.

\section{Pintura y cartografía narrada: formas de representar el mundo vivido}

A lo largo del apartado, se presentan los espacios rurales como realidades percibidas y producto de una construcción social. Lugares que simbolizan una experiencia directa y profunda del mundo, cargada de sentido y que, como tal, son la base misma de la existencia humana cotidiana. Una realidad, que como afirma Bailly (1998) "no existe fuera de nuestras construcciones y constituyen una imagen parcial de la realidad tal como la modelamos" (p. 28). La construcción de la espacialidad inicia con un conocimiento subjetivo que permite la selección de determinados elementos, con el fin de construir descripciones, explicaciones e interpretaciones: "por una representación o construcción mental de objetos, de prácticas, y de procesos espaciales” (Bailly, 1998, p. 28).

Las representaciones son tanto un proceso como un producto social. En el primer aspecto se puede interpretar como proceso de construcción de la realidad social a la que contribuye a configurar tanto como al objeto que representa. En el segundo aspecto, hace referencia al conjunto de 
creencias, valores y conocimientos que comparte un grupo de sujetos que goza de un determinado estatus social. Se articulan así las tres funciones básicas de la representación: función cognitiva de integración de lo novedoso, función de interpretación de la realidad, y función de orientación de las conductas y las relaciones sociales. Las representaciones que el ser humano realiza del espacio lo dotan de identidad, de significación, de estructura, y varían en cada una de las etapas de la vida, de las características del individuo y del momento histórico en el que vive.

Así se puede manifestar que las concepciones que presentamos acerca de ciertos conceptos espaciales, aun antes de haber tenido un acercamiento formal a los mismos, provienen de la representación construida socialmente difundida, son conocimientos socialmente elaborados y compartidos que permiten dar sentido a los acontecimientos y actos en la construcción de nuestra realidad. Para acercarnos al espacio rural y a la representación que sus habitantes tienen de él, se puede recurrir a la pintura y la cartografía narrada, puesto que permiten la representación del mundo sensible, visible o interior, que posee quien lo representa. Estas maneras de representar tienen sus raíces en la experiencia de cada día, en las ideas, conceptos y valores, resultado de los discursos y visiones del mundo.

La pintura, como un tipo de representación gráfica, permite establecer y determinar por medio de ella la manera como el dibujante entiende el espacio. Así mismo, tal como afirma Rodríguez (2008), los dibujos o representaciones gráficas son importantes por cuanto implican un acto y un contenido representativos; por esta razón se constituyen en las representaciones del mundo que él posee, pues el niño y adolescente "dibuja lo que tiene alrededor tal como él lo concibe, es decir en función del grado de madurez que ha alcanzado con su desarrollo" ( $p$. 203). Siempre liga las imágenes a las experiencias cotidianas y aquellos elementos del ambiente que son de mayor atracción.

La pintura, como cualquier obra de arte, "vuelve a ubicarnos imperiosamente en presencia del mundo vivido" (Merleau-Ponty, 2003, p. 59), es la representación "-el acto por el cual un sujeto piensa o imagina algo organizándolo conforme a categorías- interviene en efecto en toda realización humana de orden intelectual y estético (Duborgel 1981:9)" (Rodríguez, 2008, p. 207). Por ende, las representaciones no vienen directamente del objeto sino de la acción coordinada y en la experiencia con los objetos.

El arte parece ser un pequeño fragmento de ese mundo de la percepción que se nos da en nuestra práctica vital. Según Barthes (1990), la obra de arte es objeto de la intención del artífice y del observador. En ella convergen dos elementos: el Studium y el Punctum. El Studium está dado por la intención del pintor, depende del contexto y dota a la imagen de funciones; el Punctum es aquello que es capaz de salir de la imagen y provocar al observador, lo que ocurre entre el espectador y una imagen, producto de la casualidad. Sin embargo, esta relación puede resumirse "a partir de tres preguntas básicas que el artífice y el observador hacen a la imagen: ¿qué es?, ¿cómo se nos presenta? y ¿por qué?” (Gombrich, 1992, p. 14).
Así, se entiende que la pintura es un sistema de comunicación que lleva implícito una significación, es la expresión incomparable de lo que tiene quien la elabora en sí mismo, es la representación del mundo que él posee. En la pintura, como en la elaboración de un mapa, se hace una selección de la realidad desde su universo, guiado por el contenido de su mente que está condicionada por procesos psicológicos, habilidades y cualidades, conocimientos, experiencias, objetivos, entre otros. Por tanto la pintura, al igual que los mapas, habilita el reconocimiento de un territorio desde la perspectiva de sus habitantes, permite encontrar y dar a conocer realidades subyacentes, evidencia relaciones, vínculos y lazos que no siempre se tienen en cuenta y en muchos casos se desconocen.

Por su parte, la cartografía narrada o cartografía de la vida cotidiana (como también se denomina), surge en los años ochenta como una reflexión más profunda sobre el alcance humanístico en la cartografía. Autores anglosajones como Harley $(1989,1990)$, Woodward (1987) y Wood $(1978,1992)$ y recientemente en Brasil Seemann (2011) (por citar algunos) buscaron un acercamiento con los enfoques derivados de áreas no asociadas tradicionalmente con la cartografía como la antropología, la literatura, las ciencias sociales y las humanidades, para revelar la complejidad de las prácticas socioculturales e introducir elementos innovadores "para repensar los mapas, la creación de nuevas formas de representar paisajes, formas de narrar las experiencias, no necesariamente como textos, para ir más allá en las representaciones" (Hollman, 2012, p. 104).

Por tanto, deben entenderse desde el contexto de la sociedad en la que fueron producidos: "como los textos culturales, los mapas se convierten en fuente para el estudio y responden sobre el significado y geograficidad del lugar" (Seemann, 2011, p. 102). Los mapas narrados son imágenes, autorretratos, manifestaciones de las percepciones o retratos del mundo como le gustaría que se comprendiera. En la medida en que un mapa no es una producción de la verdad, sino una expresión de la experiencia en el espacio, el mapa no se limita a representar al mundo, produce el mundo, no se constituye como espejo de la realidad, sino que se concibe como diversas formas de pensar, percibir y representar el lugar; expresa valores, visiones del mundo y emociones. En otras palabras, los mapas cuentan historias que expresan y crean la realidad al mismo tiempo, revelan valores, intereses, visiones del mundo, actitudes y emociones.

Pensar el mapa como texto es la posibilidad de que el mapa sea objeto de lecturas, de interpretaciones y de juicios por parte tanto de quien lo hace como de quien lo observa:

El mapa de la vida como narrativa construye un discurso espacial como lo hace en nuestra decisión diaria. El autor presenta su propia biografía geográfica para explorar el mapa, recordando las circunstancias afectivas, lugares conocidos, por lo que se convierte en una rica forma de narrar historias de nosotros mismos (Massumi, 2013 p. 55). 
Para Wood (2013), los mapas tienen sus raíces en un profundo sentido del lugar, pues se convierten en verdaderos poemas y formas creativas de arte, que tratan de expresar la vida cotidiana y de representar lo que es invisible o lo que queda habitualmente fuera del mapa. Los mapas narrados representan la cartografía de la realidad de un lugar, en el sentido en que exponen la experiencia de cada día; acercan a la vida de un lugar desde un profundo sentido de este, sin dejar de lado la dimensión temporal. Son mapas en los que la experiencia del lugar es primordial, por ello prescinden de algunos elementos obligatorios de un mapa, como la orientación y la escala. Los mapas pueden dejar de ser un objeto técnico y altamente especializado para convertirse, en cambio, en poemas para narrar un lugar: una narración bella, creativa y absolutamente personal.

\section{Hacia una comprensión del espacio rural}

La investigación se inscribe en el enfoque cualitativo pues busca la comprensión de las interacciones de los sujetos con el espacio, los significados, las prácticas y la interpretación que los actores dan a sus acciones y experiencias. Igualmente permite comprender el contexto rural en el que los participantes actúan y la influencia que ese contexto ejerce sobre sus acciones (Vasilachis, 2006, p. 31). Se concentra en los lazos entre los individuos y el medio material, expresados en los lugares, insistiendo en la construcción social de los mismos, tomando en cuenta aspectos como su carga emotiva, estética y simbólica en cuanto a significados, valores, metas e intenciones.

El método de investigación es el etnográfico, pues posibilita conocer el mundo desde la perspectiva de los sujetos, por cuanto este es una representación de las vivencias. Se procura captar el sentido que niños y adolescentes dan a sus actos, a sus ideas, al mundo que los rodea y a los sutiles matices de las experiencias vitales para analizarlo, interpretarlo y comprenderlo antes que explicarlo. El método etnográfico permite: la descripción de las prácticas en el espacio rural en primer lugar; la necesidad de comprender los significados de las acciones y sucesos presentes en las mismas; $y$ finalmente el requerimiento de hacerlo en forma acorde al punto de vista de quienes la viven.

En primera instancia, se identifican las características particulares del espacio rural y los sujetos de investigación por medio de la observación, a través de registros de campo se contextualizan y establecen generalidades que delimitan la investigación. En segunda instancia se realiza la caracterización del lugary y los sujetos mediante la aplicación de encuestas. Posteriormente, se recopilan los datos a través técnicas de investigación. La primera técnica de investigación, permite explorar el mundo de la percepción e indagar representaciones del espacio rural presentes en niños y adolescentes. Se solicita que dibujen un espacio rural, acompañándolo con un título y una descripción de la representación y la técnica artística utilizada, sin explicación de ningún aspecto geográfico referente al espacio rural, pero si con una conversación informal como fase de inspiración relacionada con el tema de la obra.
Posteriormente, con la intención de caracterizar experiencias perceptivas de niños y adolescentes respecto del espacio rural que habitan, se recurre a la cartografía narrada como una forma de representar, comunicar y expresar ideas, conceptos y valores, resultado de las visiones de mundo. En el diseño del instrumento, se lleva a que niños y adolescentes establezcan qué tomarían en cuenta a la hora de realizar un mapa de la zona que recorren y por la que se desplazan diariamente de la casa al colegio. Se les solicita elaborar un mapa que describa lo que ven, recuerdan y conocen de la zona donde viven. Además, se les indica acompañarlo con un título y una descripción donde cuenten cómo y por qué lo realizaron, con el fin de aclarar cada una de las representaciones.

La investigación se desarrolla con 40 niños y adolescentes que habitan la zona rural, que oscilan entre 9 y 16 años de edad, de los cuales 21 corresponde a niños y 19 a adolescentes ${ }^{4}$, se seleccionan dada la posibilidad de establecer un contraste entre las diferencias e intereses por grupos de edad. La zona de estudio comprende la inspección La Esperanza ubicada en zona rural del municipio de La Mesa de la provincia del Tequendama en el departamento de Cundinamarca, Colombia. Históricamente fue el lugar de asentamiento de los indígenas panches y llegó a ser considerado el eje comercial más importante del camino que comunicaba a Bogotá con el suroeste del país en la época colonial y republicana.

Específicamente, la inspección de La Esperanza se remonta desde la construcción del ferrocarril, para conectar la capital con el río Magdalena. La relativa escasa distancia hasta Bogotá hizo fácil que desde fines del siglo pasado la población fuera el centro de atracción para el descanso y la recreación de los habitantes de la región, sobre todo de los adultos mayores atraídos por su tranquilidad. Quedan vestigios de antiguas casonas que se fueron convirtiendo en confortables quintas de recreo, hoteles o sitios de retiro, una gran variedad de cultivos y una actividad turística importante.

\section{Lectura del espacio rural. Una interpretación de la cotidianidad y de las experiencias perceptivas}

A continuación se muestran algunas creaciones pictóricas y mapas narrados elaborados por 21 niños y 19 adolescentes, asimismo sus interpretaciones y análisis a la luz de algunas consideraciones teóricas. Se da cuenta de la experiencia espacial de los sujetos que habitan el espacio rural, a partir de sus prácticas cotidianas y como expresión de la experiencia en el espacio puesto que enuncian valores, visiones del mundo y emociones.

$4 \mathrm{Al}$ referirse a niños y adolescentes no se pretende excluir las voces de las adolescentes y niñas participantes. Se hace uso de estos sustantivos genéricos y colectivos para referirse a los sujetos de investigación de manera inclusiva y general. 


\section{Las obras de arte: el mundo rural vivido de niños y adolescentes}

Para acercarnos a la realidad representada en las creaciones pictóricas de los niños y adolescentes, se hace necesario retomar algunas generalizaciones con respecto a los elementos técnicos para comprender la totalidad de la obra. Los procedimientos de los que se valen los niños para transmitir sus creaciones pictóricas son los lápices de color, mientras los adolescentes recurren a variedad de procedimientos como el carboncillo, el vinilo acrílico, entre otros. Hacen uso de colores fríos al representar los objetos de la naturaleza: el agua, las plantas y montañas; en tanto que también muestran la frescura, la calma, la soledad, la tranquilidad, y dan la sensación de mayor distancia y amplitud. Mientras que los colores cálidos son utilizados para las representaciones de las puestas de sol, los rayos del sol, y en la mayoría de las casas dibujadas; dan la sensación de vitalidad, alegría, actividad y cercanía emocional, así como el efecto de extenderse y acercarse.

En cuanto a los aspectos formales de las obras, que permiten acercarnos a la realidad representada, y establecer conexiones con el pensamiento espacial, presentan como principal punto de referencia una casa, y a su alrededor algunos elementos destacables de su entorno: montañas, cercas, carreteras, caminos, ríos, nubes y el sol; interrelacionados guardando proyección y distancia. Representan la profundidad en el horizonte y manejan relaciones de proximidad, separación, orden, cerramiento y continuidad. Hay escaso dominio de perspectiva, los objetos aparecen representados icónicamente: casas, árboles, montañas, entre otros; se presentan de manera rígida y estática, pues el movimiento se asocia con las personas que forman parte de la escena.

Se observa que el $80 \%$ de los niños y el $90 \%$ de los adolescentes representan espacios cercanos a su entorno, en la medida en que priman los aspectos más relevantes y más vivenciados pero también imprimen elementos de la imaginación. Estas obras reflejan la combinación de tres aspectos: lo que ven, lo que imaginan y lo que sienten. Por ello es común encontrar vías férreas, caminos en piedra, cercas, casas de veraneo, ríos, fincas, nevados, y montañas, que corresponden al medio en el que se desenvuelven y desplazan comúnmente. Asimismo, el género femenino dibuja espacios imaginados y de belleza natural; mientras el género masculino prefiere espacios cercanos, actividades y problemáticas de este; la razón es que los desplazamientos de las niñas son muy limitados, en comparación con los de los niños. Se observa que los niños representan en menor proporción la figura humana, en relación con altos porcentajes de representación de objetos naturales y construidos por el hombre; los adolescentes representan más los elementos naturales.
La afectividad por el lugar se puede percibir en todas las creaciones y en general se puede decir que es positiva, pues no muestran en las creaciones aspectos negativos de su entorno, por el contrario se preocupan por mostrar lo que más les agrada, o en los lugares en los que desearían estar, no dibujan aspectos desagradables, ni violentos, se asocian a la tranquilidad, la libertad, el desorden, el aislamiento y la soledad. No obstante, en las verbalizaciones que hacen del espacio sí muestran aspectos como la contaminación de los ríos, el abandono de estos lugares por el Estado, el aislamiento que no permite el acceso a los servicios, asimismo la calidez y amabilidad de su gente. Además definen lo rural y urbano de manera complementaria, siendo el tamaño y la distancia el criterio más importante tanto para niños como para adolescentes a la hora de distinguir entre una y otra entidad, noción que es normal para su edad. Esto implica, como afirma Massey (2005), que el espacio rural se comprende a través de la relación del lugar con lo que está más allá de él.

Luego de revisar las representaciones, y establecer las relaciones entre los resultados encontrados se forman diferentes grupos de percepciones que se acercan a la similitud del significado que otorgan tanto niños como adolescentes al espacio rural que habitan. A partir de estos criterios, cinco categorías fueron creadas respecto a la manera como representan el espacio rural de acuerdo a las experiencias espaciales en estos lugares:

\section{Lugar agroecológico}

Desde esta percepción del espacio rural como agroecológico, se observa que el entorno o contexto social de los niños y adolescentes se ha convertido en los principales elementos que han influido en sus percepciones. Según Merleau-Ponty (2006), en el centro donde la persona habita todas las explicaciones están disponibles, solo requiere que su intérprete incorpore estas explicaciones a través de sus sentidos y de su desarrollo cognitivo. Por consiguiente, es comprensible que en las representaciones se vean influidos por el contexto en el que predomina su diario vivir. Se genera una visión del espacio rural relacionada con "la agricultura, su organización, estructuras y actividades económicas, el paisaje agrario y de usos del suelo" (Paniagua, 2006; p. 72), con relación a la dinámica demográfica, y la influencia de un medio ambiente físico. Se observan elementos naturales propios de la zona de estudio, pues se caracteriza por ser una zona montañosa, con relieve ondulado y fuertemente quebrado, que le permite tener un clima templado y cálido una gran variedad de cultivos, una actividad turística importante, así como la presencia de fuentes hídricas que contribuyen a la producción agrícola de la zona (véase la imagen 1 ). 


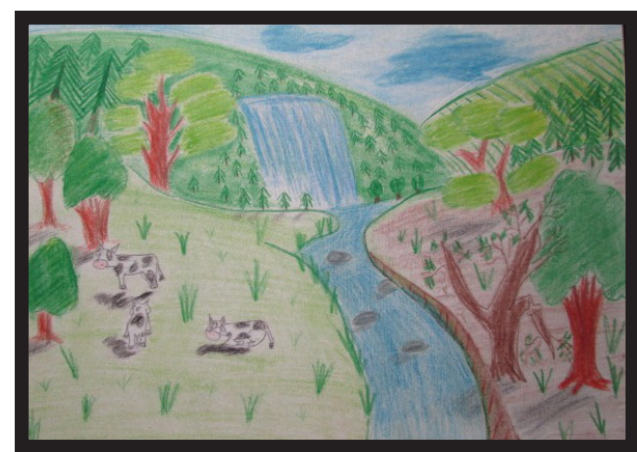

\section{IMAGEN 1}

Título: La mañana silenciosa. / Autor: Jhonny G. / Edad: 11 años Técnica: Lápices de color sobre cartón. / Año: 2013

\section{Lugar aislado}

Una de las características que les atribuyen a las zonas rurales es la falta de servicios básicos y la infraestructura, como agua potable, electricidad y comercio; a medida que se aleja de las ciudades, mayor es la falta de esta infraestructura. Así mismo, puede incluirse la falta de libre circulación por estos espacios por la demarcación con cercas y la protección de las tierras de propiedad privada. Además de este problema de aislamiento rural, se observa en algunas imágenes la sensación de soledad condicionada por la baja densidad de población, así como la poca vegetación en las zonas montañosas y en espacios cercanos a las fincas (véase la imagen 2). Observando sus trayectorias de vida, se encontró que en la mayoría representan estos espacios aquellos que llegaron por desplazamiento violento o buscando mejorar su calidad de vida. Se presenta como un lugar donde hay mayor distancia entre las personas, lo cual, de acuerdo con Tuan (1983), puede expresar pocas relaciones interpersonales. El sentimiento de soledad y aislamiento puede estar entrelazado con la idea de amplitud. De este modo, el sentimiento de soledad experimentada en algunas creaciones se relaciona con sentir que un ambiente es demasiado amplio o con baja densidad de población (Tuan, 1983).

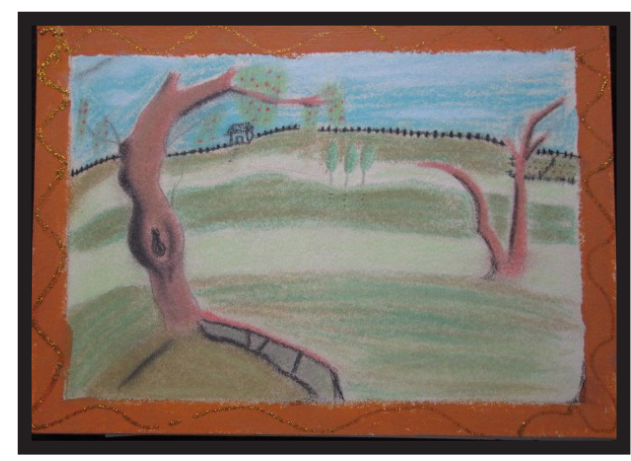

\section{IMAGEN 2}

Título: Mas allá de ti. / Autor: Marcela A. / Edad: 14 años / Técnica: pastel sobre cartón. / Año: 2013

\section{Lugar de contradicciones}

La apreciación de la vida rural, las fincas y los sitios hace que sea un atractivo para las personas que buscan una vida más tranquila y lejos de las inmediaciones del centro, dominado por el ruido y la contaminación del medio ambiente, y la vida impersonal. Estas condiciones hacen que las fincas de descanso se constituyan como un riesgo para la continuidad de las actividades agrícolas y naturales. Por tanto se pueden observar espacios en disputa, ya que los agricultores continúan realizando sus actividades. A menudo, no pueden resistir la presión impuesta por el sector inmobiliario, las fábricas y las fincas de recreo y descanso. La incidencia de los asentamientos irregulares ha dejado que algunos residentes teman por la amenaza constante de que sus sitios y sus propiedades invadidas (ver imagen 3).

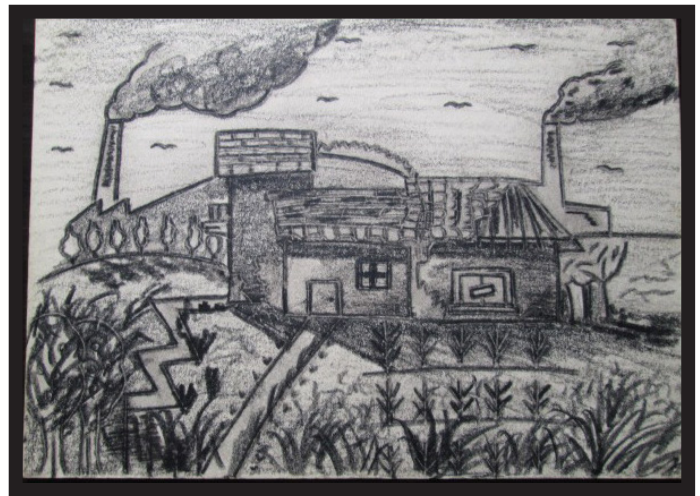

IMAGEN 3

Título: Mi vida. / Autor: Valentina N. / Edad: 13 años. Técnica: Carboncillo sobre cartón. / Año: 2013

\section{Lugar de estereotipos}

Como afirma Bosque Sendra (1992), los estereotipos "son imágenes de los lugares endurecidas en nuestra mente" (p. 101). Pueden definirse como las maneras comunes de percibir un mismo lugar, o en otras palabras, aquellas percepciones individuales que convergen en un esquema aceptable para la mayoría. Las creaciones pictóricas realizadas por niños y adolescentes reúnen varios estereotipos. En función de tales referentes perceptivos, lo rural, lejos de resumirse en un solo paisaje, se define en un conjunto de imágenes representativas de una realidad geográfica diversa y compleja. Dentro de las diferentes miradas icónicas que establecen los niños y adolescentes, han ido filtrando la realidad y fijándose en unos paisajes e ignorando otros, de acuerdo con unas escalas de valores y unos contextos económicos, sociales y culturales que han ido evolucionando a lo largo del tiempo; que se deriva un hecho de gran trascendencia para la vida perceptual de los humanos, "a saber, el hecho 
de que nuestra mente requiere la sujeción a ciertos esquemas simplificadores de la realidad" (Bosque, 1992, p. 124). De esta forma, se han ido configurando las representaciones formales que definen los espacios rurales en imágenes universalmente reconocidas por su fuerza connotativa. Pero debemos reconocer que esos estereotipos conllevan alguna desviación de la realidad, asociando el espacio rural a simplificaciones de la idea de naturaleza, reducido a escenografía paisajística, como una óptima representación de lo natural: prados verdes, colinas con bosquetes, vacas y ovejas pastando, campesinos trabajando, pueblos pequeños, ríos puros, casas, sol, arcoíris, cielos azules, entre otros, encarnado en vistas amables y acogedoras, que comunican principalmente la idea de equilibrio entre naturaleza y cultura (véase la imagen 4).

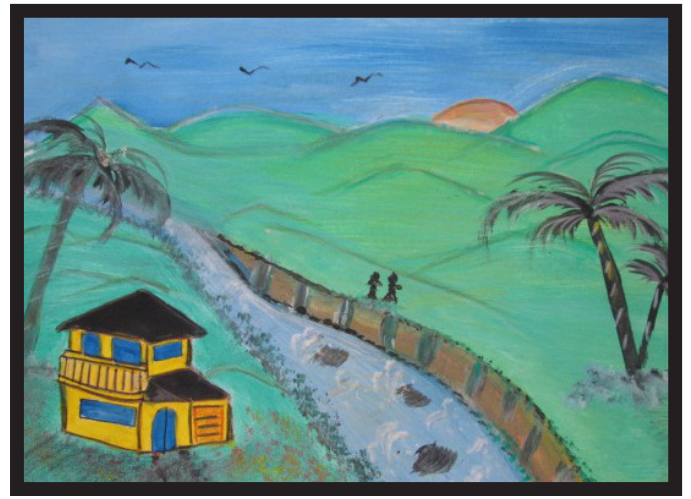

\section{IMAGEN 4}

Título: El Paraíso. / Autor: Ángela B. / Edad: 10 años

Técnica: vinilo sobre cartón. / Año: 2014

\section{Lugar de libertad}

En esta categoría constituye un componente importante la calidad de vida, sobre todo en términos de beneficios sociales y del medio ambiente, las consideraciones acerca de las cualidades de los espacios rurales como zonas de predominio del entorno natural, y el bajo número de habitantes. Por lo tanto, las sensaciones desagradables que surgen de las prácticas en las grandes ciudades determinaron en los sujetos deseos de vivir en otro mundo, libre de estas concepciones de la vida que dictan qué hacer. Evidencian diferentes maneras de relacionarse con el mundo exterior, para los habitan allí desde hace más de diez años, como los que llevan un año, los espacios rurales se constituyen en aquellos que permiten estar fuera del ritmo que imponen las ciudades. Se puede decir cómo afirma Tuan (1983) que se constituyen en símbolo común de la libertad al ser percibidos como abiertos a la mirada y el pensamiento (ver imagen 5).

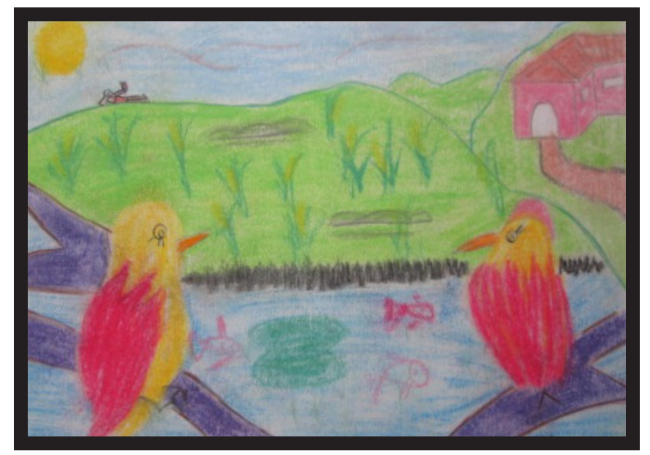

IMAGEN 5

Título: El campesino relajado / Autor: Natalia R. Edad: 15 años Técnica: tizas de color sobre cartón / Año: 2013

\section{Narraciones cartográficas: mapeo de experiencias perceptivas}

Cada uno de estos mapas corresponde a una lectura individual de los niños y adolescentes, lo que involucra un proceso cognitivo de la representación interna (experiencia, conocimientos científicos) a la representación exterior (imágenes, palabras, signos). Por lo tanto, los mapas narrados se analizan como un producto de la cognición del individuo con referencia a la lectura e interpretación de los diferentes paisajes que están presentes en el espacio; en otras palabras, es la construcción de una "mirada" sobre los contextos, sobre lo que ocurre en la sociedad. Los mapas narrados abren la posibilidad de observar y reconocer cómo niños y adolescentes integran elementos de la realidad y la cotidianidad, e identificar sus lecturas e interpretaciones del espacio.

Estas representaciones cartográficas del espacio pueden dar la impresión de ser muy personales, ya que cada individuo tiene la libertad de producir el mapa narrado a su manera. Para superar esta situación, se organizan algunos criterios de análisis y selección de la información contenida en los mapas, para establecer los parámetros de interpretaciones a las producciones cartográficas. En primera instancia, en los mapas de niños y adolescentes se nota la influencia de la experiencia académica en las representaciones, particularmente cuando incluyen en los mapas ciertas convenciones: los puntos cardinales, la utilización de símbolos convencionales, las asociaciones de los colores azul para el agua y verde para la vegetación.

El análisis de estos mapas nos permite seleccionar algunas categorías de análisis, como: área geográfica, aspectos lineales, aspectos puntuales y usos del suelo. En este sentido, se utiliza la propuesta de Santos (1985), que cuenta con categorías para la comprensión de la producción del espacio, que son: forma, función, estructura y proceso. La función principal que se le asigna al espacio rural tiene que ver con el sistema económico y la prestación de servicios; el $32 \%$ de los mapas le asignan al espacio las funciones turísticas y el $22 \%$ lo describen como espacio agropecuario; con ello viene relacionada toda la infraestructura comercial (tiendas, restaurantes, galpones, cultivos de flores, frutas, café, palma y caña) y recreacional (hoteles, fincas de veraneo, piscinas, espacios 
ecológicos, centros históricos). El $17 \%$ le otorga un valor histórico, con relación a las huellas dejadas desde la Colonia y la economía ferroviaria de nuestro país (ver imágenes 6 y 7 ).

El 10\% de los mapas representados otorga la función de flujos mostrando los desplazamientos diarios en el espacio relacionados con las prácticas educativas que efectúan. El 7,5\% muestra un espacio social, escenario de encuentro y contactos con familiares, amigos, vecinos y conocidos. El 7,5\% evidencian las problemáticas del espacio, los acontecimientos, fenómenos y procesos que son responsables de la modificación del espacio rural, como la urbanización de suelos de cultivo, la explotación laboral del campesino y la modernización a partir de la infraestructura eléctrica. El $5 \%$ de los mapas se refiere a la valoración del medio a través de los sentimientos que despierta, y están relacionados con experiencias placenteras del lugar.

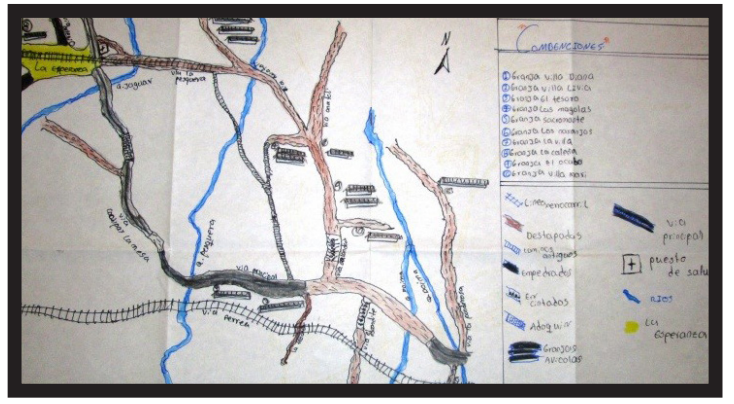

\section{IMAGEN 6}

TÍTULO: Industrias avícolas de la región

DESCRIPCION: se intenta mostrar las granjas avícolas de nuestra región en particular y ver la cantidad de lugares que se dedican a esta labor, porque es una parte de la economía de la región y una fuente de ingresos para la comunidad. Autor: Julio R. / Edad: 11 años. / Año: 2014

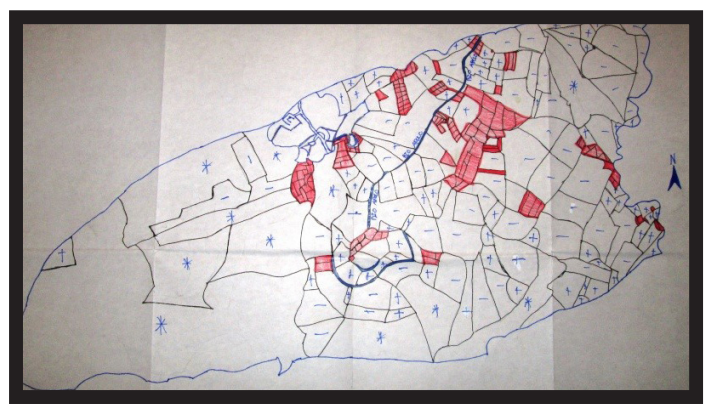

\section{IMAGEN 7}

TÍTULO: Las migas de La Esperanza

DESCRIPCIÓN: si La Esperanza es una vereda pequeña, pues por obvias razones las fincas que forman parte de La Esperanza son muy pequeñas, entonces son como migas en el mundo. Quise hacer este mapa con las divisiones de los terrenos porque estoy viendo que las personas que comercializan vendiendo propiedades están viniendo a lugares como este a comprar propiedad o a veces hasta adueñarse vendiéndolas más pequeñas, urbanizando zonas rurales como está ocurriendo aquí.

Autor: David V. / Edad: 16 años. / Año: 2014
Finalmente, hay que mencionar que los mapas narrados representan espacios llenos de lugares y cosas, en los que casi nunca aparecen las personas en su relación directa con el espacio, salta a la vista que solo hay dibujos de la figura humana en el $10 \%$ de los mapas. La variedad de representaciones cartográficas muestra distintas formas o maneras de pensar el espacio en los niños y adolescentes, algo clave para pensar el espacio pues da la idea de que no es algo fijo, unívoco sino que puede tener muchos significados. De esto se puede inferir que se destacan distintas maneras de representar: unos lo hacen de manera abstracta, otros figurativamente, otros dibujan como si estuvieran mirando por una cámara, y otros reflejan una aproximación mental rigurosa del recorrido escolar. En su totalidad los mapas muestran un espacio lleno, abigarrado, repleto, detallado; mientras otros lo representan más espacioso, dan idea de profundidad, movimiento y continuidad, esquematizando más. En definitiva se trata de un espacio muy interiorizado, conocido y dominado que se puede detallar y situar relaciones dentro de él, denota gran actividad y recorrido del mismo.

Las experiencias perceptivas cartografiadas por los niños y adolescentes están relacionadas con dos planteamientos. Primero, desde los planteamientos estructurales o descriptivos (aspectos puntuales, areales y lineales), que analizan los elementos que permiten la organización cognitiva del espacio y son necesarios para que los sujetos puedan orientarse dentro del entorno rural. La intensidad con que son percibidos y el número que los individuos reconocen varían según las características morfológicas del espacio rural y según factores personales, entre los que sobresalen: grado de conocimiento del espacio, el tiempo de residencia en ella, la distancia de la vivienda al lugar de estudio, las formas de desplazamiento utilizadas habitualmente, y la etapa de pensamiento en que se encuentre.

Se pone de manifiesto la existencia de diferentes mundos rurales en su interior, puesto que en cualquiera de los mapas narrados individuales se puede apreciar cómo cada persona estructura y organiza el espacio de forma diferente, reflejando su propia visión, estilo de vida y sentimientos. La riqueza de los mapas narrados guarda también relación con la edad, los grupos sociales, la familiaridad con el medio vivido y el estilo de vida. A ello hay que añadir la tendencia general de los niños y adolescentes a valorar afectivamente su propio entorno, al tiempo que estructuran el mapa narrado alrededor del lugar en que residen.

Segundo, desde el enfoque preceptivo, que refleja los sentimientos de los niños y adolescentes acerca del entorno con vista a la toma de decisión y comportamiento. Las prácticas espaciales de los niños y adolescentes dependen no solo de la percepción y localización referencial de los elementos de paisaje sino de cómo son sentidos e interpretados. Teniendo en cuenta los elementos apreciativos evidenciados en los mapas narrados se establecen elementos comunes: 
- Las áreas rurales son valoradas en función del conocimiento que se tiene de ellas, y de los criterios y fines de la acción.

- Determinadas áreas son valoradas por una carga simbólica que se ha desarrollado en un contexto cultural y se hace presente. Es el caso del centro histórico de la inspección y los lugares más característicos, que representan la herencia cultural y memoria colectiva del lugar; o el simbolismo sentimental que encierra para aquellos que han vivido durante su infancia.

- La existencia de estrechas relaciones entre los individuos y el medio, que suscita el interés por el "sentido del lugar" o sentimiento de unión con el lugar en que se vive, arranca de la propia experiencia y se relaciona con las ideas de familiaridad que crean vínculos de afinidad e identidad. Son varios los lazos de afecto que muestran las representaciones cartográficas, entre ellos está el sentido del lugar social como escenario de encuentro y contactos con familiares, amigos y vecinos. El sentido de lugar instrumental como lugar de producción agropecuario; lugar nostálgico dominado por un sentimiento apoyado en situaciones vivenciales o emocionales; lugar como escenario en el que transcurre la vida de las personas; y lugar arraigado o sentimiento de familiaridad e identificación con el medio en que reside.

- Los significados atribuidos al espacio rural tienen que ver con las prácticas sociales y la función principal que se le asigna al espacio rural. La primera tiene que ver con el sistema económico y la prestación de servicios de acuerdo a las funciones turísticas y agropecuarias. La segunda tiene que ver con el valor histórico, en relación con las huellas dejadas desde la Colonia y la economía ferroviaria de nuestro país. La tercera tiene relación con los desplazamientos diarios en el espacio relacionados con las prácticas educativas que efectúan. La cuarta está relacionada con el espacio rural como escenario de encuentro y contacto con familiares, amigos, vecinos y conocidos. Finalmente, están los acontecimientos, fenómenos y procesos que son responsables de la modificación del espacio rural, como la urbanización de suelos de cultivo, la explotación laboral del campesino y la modernización a partir de la infraestructura eléctrica.

La ruralidad puede ser vista entonces como un espacio de la cotidianidad y reflejo de la misma, puesto que niños y adolescentes toman como escenario de sus actividades cotidianas su entorno inmediato y sobre este desarrollan sus prácticas, experiencias y vivencias; está constituida por un conjunto de ritmos y rutinas estructurados por la localización en el espacio y en el tiempo. Así el espacio rural se constituye como construcción social en la medida en que en él confluyen tres ámbitos: los espacios de representación o espacios vividos por sus habitantes; las prácticas espaciales o lo que realizan cada sociedad; y las representaciones del espacio que tienen que ver con el espacio dominante en cualquier sociedad. De esta manera, hay que tener en cuenta distintas características que enriquecen la categoría de ruralidad y ayudan a la construcción de los espacios rurales en la actualidad.

\section{Consideraciones finales}

El reconocimiento de un espacio desde la perspectiva de sus habitantes permite encontrar y dar a conocer realidades subyacentes, evidencia relaciones, vínculos y lazos que no siempre se tienen en cuenta y en muchos casos se desconocen. Al acercarse al análisis del espacio rural a través de sus representaciones, se parte desde la realidad material y formal a la más representativa, simbólica y abstracta de las imágenes. Las representaciones que el ser humano realiza del espacio lo dotan de identidad, de significación, de estructura, y varía en cada una de las etapas de la vida, de las características del individuo, del momento histórico en el que vive, en función de un determinado estatus social, de las experiencias escolares y de la vida social entera.

Las creaciones pictóricas permiten estudiar el mundo en el que las personas piensan, viven, actúan y se relacionan, dando énfasis al papel de la experiencia humana y al significado de sus relaciones con sus ambientes geográficos; intenta específicamente entender cómo las actividades y los fenómenos geográficos revelan la cualidad de la conciencia humana. Así mismo, expresan el espacio vivido que se constituye como el espacio frecuentado, el área de las prácticas espaciales, los lugares en torno a los cuales se construye la existencia individual, que se enriquece de los intercambios sociales, las cargas emotivas, las imágenes y los conceptos individuales.

Así mismo, la pintura es un recurso y un medio excelente con el cual trabajar en investigación, ya que es una actividad altamente motivadora, tanto a nivel social, de hábitos y actitudes, y a nivel didáctico. A nivel social: favorece la expresión y comunicación a través del dibujo, valorar y respetar las producciones de los demás. A nivel de hábitos y actitudes: favorece y refuerza la organización espacio-temporal, desarrolla hábitos y destrezas, fomenta actitudes cooperativas, críticas, creativas y de investigación. A nivel didáctico: favorece el carácter lúdico, fortalece la motivación, desarrolla la observación y experimentación como fuente de conocimiento, y favorece la reflexión y la creatividad.

Respecto a los mapas narrados como técnica de investigación se convierten en fuente para el estudio y responden sobre el significado y la geograficidad del lugar, del contexto de la sociedad en la que fueron producidos. Así, facilitan la comprensión espacial de las cosas, los conceptos, las condiciones, los procesos o acontecimientos en el mundo. Toda elaboración de mapas narrados sobre el espacio constituye un producto individual, en la medida en que es obra de una persona. Implica decisiones de cada sujeto sobre lo que considera relevante o pertinente 
del espacio por sus características históricas, estéticas, simbólicas, entre otras, tanto en forma positiva como negativa. Sin olvidar que la percepción social del autor de cada mapa puede estar influida por sus prácticas y experiencias singulares en torno al espacio o lugar, estas decisiones determinarán lo que incluirá en el mapa y cómo lo presenta. Así, la cartografía narrada se acerca mucho en corresponder con la realidad espacial que experimenta el individuo en su cotidianidad y mucho más aún con la manera en la que se la auto-representa que alude a una interioridad mental que guía el desplazamiento y la estructura del comportamiento espacial del individuo.

En este contexto, si bien tales mapas expresan diferentes tipos de información, conviene recordar que son elaborados por individuos que comparten variables sociales como la edad, el género, niveles de información, como cuestiones de índoles práctica, para utilizarla de acuerdo a sus diversas necesidades. Por lo anterior, no resulta extraño que, además de los elementos subjetivos que se proyectan en los mapas narrados, observemos tendencias, recurrencias y ciertos patrones en la forma de imaginar y representar el espacio. Dichas tendencias se relacionan con la forma como se concibe la organización, estructura y delimitación del espacio, y los hitos y símbolos que constituyen los elementos que identificatorios de un lugar.

Los mapas narrados ofrecen como posibilidad la visibilización del saber espacial local y ciertos atributos instituyentes que le fueron otorgados. En últimas, la indagación en los mapas narrados puede postular una noción de espacio de amplio dinamismo y consciente de las múltiples tensiones inmersas de su apropiación, y consolidar un estudio espacial que apela al conocimiento compartido. La variedad de representaciones cartográficas muestra distintas formas o maneras de pensar el espacio en los niños y adolescentes, algo clave para pensar el espacio pues da la idea de que no es algo fijo, unívoco, sino que puede tener muchos significados.

Las concepciones del espacio rural, presentes en niños y adolescentes que lo habitan, están relacionadas con lo cultural pues cada grupo social puede generar su propia representación espacial; la heterogeneidad de las distintas actividades rurales; los flujos de producción y de comercialización de los productos, la movilidad de las personas y las mercancías, entre otras. Las concepciones están ligadas a una cierta transformación, sobradamente reconocida, de una visión de producción, a una idea de consumo en los espacios rurales, que no se produce de manera uniforme espacialmente, pero que dota al individuo o a las agrupaciones de individuos de prácticas económicas y sociales. Asimismo, el espacio rural adquiere un valor y conforma nuevos espacios idealizados, con una carga simbólica para los propios habitantes de las comunidades. Todo ello reconfigura necesariamente la relación local-comunidad-lugar, al alterarse los componentes de esta relación y su significado e incrementarse los procesos sociales, culturales y económicos.
Así, lo rural, lejos de resumirse en un solo paisaje, se define en un conjunto de imágenes representativas de una realidad geográfica diversa y compleja. Dentro de las diferentes miradas icónicas que establecen los niños y adolescentes, han ido filtrando la realidad y fijándose en unos paisajes e ignorando otros, de acuerdo con unas escalas de valores y unos contextos económicos, sociales y culturales que han evolucionado a lo largo del tiempo. De esta forma, se han ido configurando las representaciones formales que definen los espacios rurales en imágenes universalmente reconocidas por su fuerza connotativa.

\section{Referencias bibliográficas}

Akira, T. (2013). Fenomenologia, mundo-da-vida e crise das ciências: a necessidade de uma geografia fenomenológica. Geograficidade, 3 (2). Disponible en: http://www.uff.br/posarq/geograficidade/ revista/index.php/geograficidade/index

Alario, M. \& Molinero, F. (1994). La dimensión geográfica del desarrollo rural: una perspectiva histórica. Revista de Estudios Agro-Sociales, 169, 53-87.

Bailly, A. (1998). La geografía imagen del mundo. En: Métodos y técnicas cualitativas en geografía social. Barcelona. Oikos-Tau.

Barthes, R. (1990). La cámara lucida. Nota sobre la fotografía. Barcelona: Paidós.

Bosque Sendra, J. (1992). Prácticas de la geografía de la percepción y de la actividad cotidiana. Barcelona: Ed. Oikos-Tau.

Buttimer, A. (1992). Fénix, Fausto y Narciso. Esperanzas y riesgos del humanismo en geografía. En: Geografía y humanismo. Barcelona: Ed. Oikos-Tau.

Capel, H. (1975). La definición de lo urbano. Disponible en: http://www. ub.edu/geocrit/sv-33.htm

Gombrich, E. H. (1987). Nuevos estudios sobre la psicología de la representación pictórica. Alianza Forma.

Gombrich, E. H. (1992). Sobre la interpretación de la obra de arte. El qué, el por qué y el cómo. Disponible en: http://www.unav.edu/documents/29070/369971/ra05.pdf

Hollman, V. (2012). Mapas para narrar un lugar en el mundo. Estudios socioterritoriales. Revista de Geografía, 11. Disponible en: http:// www.cig.org.ar/docs/N\%C2\%B0\%2011/Hollman.pdf 
Lindón, A. (2006). Geografías de la vida cotidiana. En: Tratado de geografía humana. Buenos Aires: Anthropos.

Massumi, Â. (2013). Natureza(s) da Cartografia. Revista Geograficidade, 03. Disponible en: http://www.uff.br/posarq/geograficidade/ revista/index.php/geograficidade

Merleau-Ponty, M. (1975). El mundo percibido. En: Fenomenología de la percepción (pp. 219-376). Barcelona: Editorial Península.

Merleau-Ponty, M. (2003). El mundo de la percepción. Siete conferencias. México: Fondo de Cultura Económica.

Paniagua, Á. (2004). La geografía rural, entre el peso de la regulación y las orientaciones constructivistas (pp. 123-134). Disponible en: http://ddd.uab.es/pub/dag/02121573n43p123.pdf

Rodríguez de Moreno, E. (2008). Diagnóstico sobre nociones y manejo de conceptos sobre el espacio geográfico. En: Cotidianidad y enseñanza de la geografía (pp. 201-275). Grupo Geopaideia. Bogotá: Ed. Códice.

Santos, M. (1985). Espacio y método. São Paulo: Editorial Nobel.

Seemann, J. (2011). Cartografia do Cotidiano, Mapas Não Convencionais e um Atlas de Narrativas. Revista Geograficidade, 1 (1). Disponible en: http://www.uff.br/posarq/geograficidade/revista/index. php/geograficidade
Seemann, J. (2013). Estratégias pós-fenomenológicas para cartografar uma região: narrativas, mapeamentos e performance. Revista Geograficidade, 3 (2). Disponible en: http://www.uff.br/posarq/ geograficidade/revista/index.php/geograficidade

Soja, E. (1997). El tercer espacio. Ampliando el horizonte de la imaginación geográfica. En: Geográphikos, 8, 71-76.

Tuan, Y. (1976). Geografía humanística. En: Annals of the Association of American Geographers. № 66 . Disponible en: http://www.angelfire.com/ma2/geouruguayleo/geohumanist.html

Vasilachis, I. (2006). Estrategias de investigación cualitativa. Barcelona, Editorial: Gedisa.

Wood, D. (1992). El poder de los mapas. Disponible en: www.geocities. ws/nievas_ies/.../El_poder_de_los_mapas.pdf

Wood, D (2013). Everything Sings: Maps for a Narrative Atlas. Disponible en: http://www.deniswood.net/ 